\title{
The Confusion of Design and Facilities in Good Manufacturing Practice Requirements among Industries in Malaysia
}

\author{
Mohd Bakri Jali ${ }^{12^{\star}}$, Maaruf Abdul Ghani², Norazmir Md Nor ${ }^{3}$ \\ 1SIRIM Training Services, Persiaran Dato Menteri, 40700 Shah Alam, Selangor, Malaysia \\ ${ }^{2}$ Faculty of Science \& Technology, Universiti Kebangsaan Malaysia, 43600 Bangi, Selangor, Malaysia \\ ${ }^{3}$ Faculty of Health Sciences, Universiti Teknologi MARA, 42300 Puncak Alam, Selangor, Malaysia
}

\begin{abstract}
Food manufacturing operations need to fulfil regulatory requirements related to hygiene and Good Manufacturing Practice (GMP) to successfully market their products as safe and high quality products. GMP is a component of the food safety system to ensure the control of public hygiene and environmental conditions of the food production process. This study aims to investigate the confusion over design and facilities elements among food industries through qualitative technique. Design and facilities elements lay a firm foundation for GMP to ensure food hygiene and should be used in conjunction with each specific code of hygiene practice and guidelines.
\end{abstract}

(c) 2016. The Authors. Published for AMER ABRA by e-International Publishing House, Ltd., UK. This is an open access article under the CC BY-NC-ND license (http://creativecommons.org/licenses/by-nc-nd/4.0/).

Peer-review under responsibility of AMER (Association of Malaysian Environment-Behaviour Researchers), ABRA (Association of Behavioural Researchers on Asians) and CE-Bs (Centre for Environment-Behaviour Studies), Faculty of Architecture, Planning \& Surveying, Universiti Teknologi MARA, Malaysia.

Keywords: food safety; food hygiene; GMP; HACCP

\subsection{Introduction}

The Hazard Analysis Critical Control Point (HACCP) system practiced now is not a system that stands on its own. HACCP requires another system component known as Prerequisite Programmes (PRP). PRP is practiced in the food safety system based on the requirements of Good Manufacturing Practice (GMP). GMP is essentially a component of the system to ensure the control of public hygiene and environmental conditions of the food

\footnotetext{
* Corresponding author. Tel.: +6-019-389-2321; Fax: +6-03-5544-6233.

E-mail address: mbakri@sirim.my
}

2398-4287 @ 2016. The Authors. Published for AMER ABRA by e-International Publishing House, Ltd., UK. This is an open access article under the CC BY-NC-ND license (http://creativecommons.org/licenses/by-nc-nd/4.0/).

Peer-review under responsibility of AMER (Association of Malaysian Environment-Behaviour Researchers), ABRA (Association of Behavioural Researchers on Asians) and CE-Bs (Centre for Environment-Behaviour Studies), Faculty of Architecture, Planning \& Surveying, Universiti Teknologi MARA, Malaysia.

DOI: http://dx.doi.org/10.21834/e-bpj.v1i3.361 
production process (Wallace \& William, 2001). On the other hand, HACCP is based on seven principles used to develop the HACCP plan to ensure control of significant food hazards through the critical control point (CCP). The practice of a food safety system into the practice in the industry is implemented through certification received either from the government or through an accredited certification body. Compliance with the requirements of GMP and HACCP is by reference to the standard requirements adopted by the countries concerned. For example, in Malaysia, the requirements of GMP and HACCP, respectively refer to the standards of MS 1514: 2009-Good Manufacturing Practice for Food and MS 1480: 2007-Food Safety According to Hazard Analysis and Critical Control Point. Compliance with the food safety requirements will be assessed by the auditor of the authority or an accredited certification body. However, before the food safety system is practiced by the industry, this system should be developed by the industry itself or through consultation of the authoritative consultant in the field of food safety.

The practice of GMP and HACCP by the food industry should be ensured effectively to guarantee the hygiene and safety of products of any hazard found in food production. In the development and implementation of GMP and HACCP food safety systems, there have been numerous inconsistencies or confusions over the interpretation of both standard requirements that serve as compliance guidelines (Losito et al., 2011). Inconsistency or confusion of the issues concerning GMP and HACCP certainly affect the effectiveness of the practice by the industry. Many of the issues that were reported by researchers were due to the lack of uniformity or confusion (Panisello \& Quantick, 2001; Losito et al., 2011; Wallace et al., 2014) in GMP and HACCP practices, which will be discussed later. Inconsistencies or discrepancies do not only affect the effectiveness of the practices of GMP and HACCP, but a very serious impact on the real intention of HACCP to ensure the safety of products manufactured with costeffectiveness. For example, confusion in determining the materials for the construction industry will have to bear the enormous costs for a long time for the purpose of maintenance, cleanliness, and if forced to make a renovation again. While errors in determining the hazards in the production process steps can lead to CCP (critical control point) in large numbers resulting in the implementation of HACCP becoming too complex, and the materials and labour used for inappropriate matters (Bai et al., 2007).

\subsection{Literature Review}

GMP is the preliminary step for a company before implementing the HACCP system. GMP focuses on issues concerning production environment, structure and infrastructure in the premises in order to manufacture products that are high in quality and safe for consumption (MOH, 2010; DVS, 2013). Celaya et al. (2007) confirmed that the companies within the food and beverages industry have a higher chance to implement the HACCP system if they first fulfilled the requirements in the Pre-Requisite Program (PRP) as compared to those that did not fulfill these requirements. The development of GMP is not something to be taken lightly as it requires a long period of time, large expenses and dedication especially concerning the implementation of standard operating procedures' (SOP) documents as well as records of its implementations (Lombardo, 2014).

The design and facilities is the first requirement in the GMP which covers the location, design and layout, floor, walls, ceiling, doors, windows, surfaces in contact with food, water supply, drainage, toilets, changing rooms, personnel hygiene facilities, air quality and ventilation, lighting and storage (MS 1514: 2009). Design and facilities of a food-based premise needs to keep sanitation and sanitary design at its core (Graham, 2004). Sanitary design is the engineering structure and design in food handling, processing, storage facilities and equipment in preparing a clean processing environment, as well as the manufacturing of products which are consistently free of contamination, trusted and economical. The more sensitive a product is towards microbiological hazards, the higher attention that needs to be paid to the sanitation and sanitary design (Lelieveld et al., 2005). The sanitation process is more effective when the sanitation and sanitary design is combined together. The American Meat Institute Facility Design Task Force issued 10 principles in equipment sanitary design and 11 principles in facilities sanitary design (Cramer, 2008). The aim of these principles is to prepare a guideline for the food industry in the design and engineering of equipment and buildings, the construction of food-based premises in order to maximize the prevention of food hazards, maximizing hygiene and sanitation, maintain and increase the shelf life of the products 
and to increase the safety of the products by decreasing any diseases brought on by the food as well as avoiding injuries and product recalls (Cramer, 2003).

There have been many articles published that have explained the requirements of design and facilities of GMP (Federal Register, 1997; Cramer, 2003; Graham, 2004; Lelieveld et al., 2005; Powitz, 2005; MOH, 2010; Moerman, 2010; Schmidt \& Erickson, 2014). Besides that, many studies have also reported on issues and problems relating to design and facilities, some of which were insufficient equipment, errors in layout plan and equipment (Panisello \& Quantick, 2001), high amounts of non-conformities of design and facilities in the premises of small and medium industries (Domenech et al., 2011) as well as insufficient rooms to work in, cross contamination in the production process and a lack of clear segregation of hygienic areas (Mukentwali et al., 2013). The audit ISO 9001 and HACCP/ISO 22000 reports in the West Balkans also reported non-conformity towards existing layout plans (8.6\%) and cross contamination (8.9) (Djekic et al., 2011). The insufficiencies in the physical premises plans contributes up to $37 \%$ of non-conformity towards the requirements of the food safety systems in the milk industry in Turkey (Karaman et al., 2012). A study in Malaysia also reported weaknesses in the small and medium industry in obeying the requirements in design and facilities (Hasnan et al., 2014). However, there have been no detailed study on the problem or confusion that is present regarding design and facilities within the Malaysian industry context. This study aims to deeply identify the problems or confusions in design and facilities and the application with sanitation and sanitary design concepts in the selected industries through direct observations in the hopes that improvements can be made.

\subsection{Methodology}

An ethnographic method was employed in this study. Ethnography is defined as the practice of anthropological research based on live observation and description of people's way of life or work. On the other hand, it is defined as the study and systematic recording of human cultures or habits in order to produce a descriptive work from such research. Besides that, the ethnography method was used where the intent is to provide a detailed and in-depth description of everyday life and practice. The surroundings of the study were observed from the point of view of the subject whereby the participants acted as the subjects. Furthermore, there are two major types of ethnographic studies that are being applied in this research, namely observations and photo taking. The observations were made and followed by photo taking that were applied in this research and used in order to document the actual design and facilities in the industry. Participant observations were made via an engagement in the field setting or place where the ethnography took place. This is one of the primary sources of ethnographic data. Observation and picture taking for the design and facilities only involved three companies as in Table 1. All food companies have obtained HACCP certification for their products. Products manufactured by the industries are different. However, the practice is the same food safety system based on the requirements of MS1514: 2009 and MS1480: 2007.

Table 1. Demographic data of companies involved in the GMP observation

\begin{tabular}{llll}
\hline Company code & Product & Operational year & Certified duration \\
\hline A & Pre-mixed coffee & 2008 & 1 year \\
B & Frozen food & 2000 & 7 years \\
C & Paste \& drinking water & 1997 & 8 years \\
\hline
\end{tabular}

The diversification of products from company respondents including pre-mixed coffee, frozen food, paste and drinking water allows the assessment of the level of design and ease of application needs through the different products made from the production environment. In the production of pre-mixed coffee, for example, a dry work environment is required compared with the production of frozen food, paste and drinking water. The conditions of a dry work environment will affect the choice of building materials and necessary design facilities. Meanwhile, the production of frozen food requires a lot of diversity of raw materials and complicated preparation methods, and production facilities are designed for cooling, heating and extreme refrigeration (blast freezing). The design and facilities required in the production environment of different products give rise to various aspects, such as plan 
layout design, selection and use of building materials as well as facilities, maintenance, and cleanliness. The time of certification is also necessary to ensure that the respondent companies have been audited and certified by GMP and HACCP, also serving as the benchmark for the company's continued compliance practices to the requirements of GMP and HACCP principles. Companies B and C were found to have adopted GMP and HACCP for about 7-8 years compared with Company $A$ that is certified for one year. The difference in the period of certification can help with the assessment of the design and new features compared to the old one. The time of certification can be the size of a safety culture within the company (Griffith et al., 2010a; Griffith et al., 2010b) and the level of competence of staff or a team in managing and implementing the HACCP food safety system.

\subsection{Findings \& Discussion}

\subsection{Floor}

Photo $\mathrm{A}$ in Fig. 1 shows the use of epoxy because the resulting product is a dry product, which is pre-mixed coffee. The use of epoxy is suitable for this type of industry because only a very limited use of water is needed for cleaning and sanitation purposes. In addition to providing a flat and smooth surface, it is easy for cleaning and sanitation. If the means of transport for the transfer of products are not heavy materials such as a hand forklift, the surface is resistant and durable. Photo $C$ in Fig. 1 shows the use of ceramic tiles painted with an epoxy floor as the building material in the production of paste and drinking water industrial products. The purpose of using epoxy on the surface of the tile is to remove stains or scratches on the tile. This situation occurs because the joint allows pollution sloughing the tiles and epoxy on the surface of the tiles that cause the adhesion of dirt and microbes (Cramer, 2003; Moerman, 2010; Schmidt \& Erickson, 2014). This shows the confusion of the industry to make the selection of building materials for the floor. MS1514: 2009 and the Federal Register (1997) have expressed the surface of walls, partitions and floors should be made of materials that are resistant and free of toxic effects. The floor surface must have a slope of 1-2\% (Lelieveld et al., 2005).

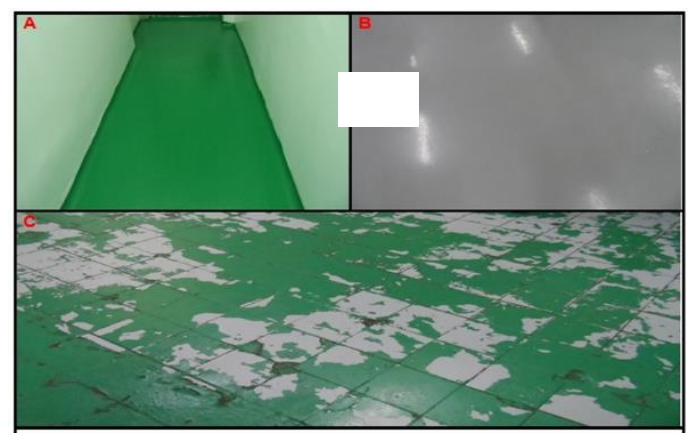

Fig. 1. Floor materials

There are many types of materials available for flooring such as ceramic tile, quarry tile, epoxy materials, densitop, polyurethane, poly vinyl and polished heavy-duty concrete. Tiles and epoxy floors as building materials are most frequently used in food premises in Malaysia, especially among the small and medium industries. Tile is a construction material that is readily available, inexpensive and easy to maintain compared to other building materials. However, the installation of tiles establishes a joint between them that can cause difficulties in maintenance, especially when there is a fracture. This may lead to the growth of microorganisms due to the presence of stagnant water and leftover debris in the fractures (Smith, 2006; Moerman, 2010; Schmidt \& Erickson, 2014). Frozen food processing industries use tile as the material of choice because of its durability in wet areas as well as being anti-rust, resistant to fluctuations in temperature and extreme conditions, and easy to repair (Cramer, 
2003; Moerman, 2010). The use of epoxy in wet areas is less suitable as the coating material will crack and peel in one period (Moerman, 2010; Schmidt \& Erickson, 2014). Epoxy cracks may also occur due to an inappropriate means of transport for the transfer of materials in the premises. The selection of densitop flooring is compatible with the nature of the industry involved in the processing of frozen food. Although Cramer (2003) and Moerman (2010) stated that the use of tiles is more appropriate to this industry, the company (Photo B) chose densitop for their flooring plan. Using densitop flooring is much better than tile in producing a flat surface that is smooth and resistant to corrosion or cracks although the price is quite high.

\subsection{Wall}

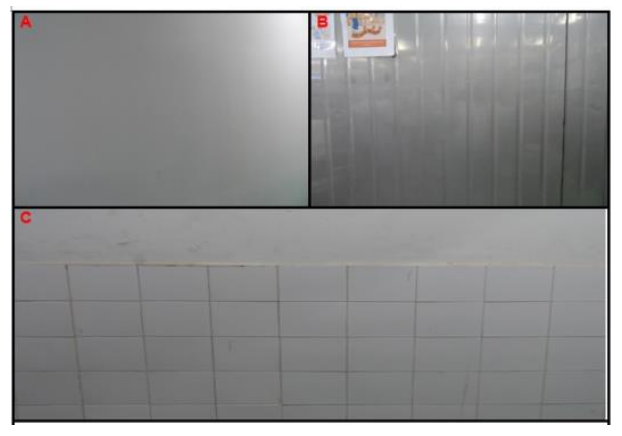

Fig. 2. Wall materials

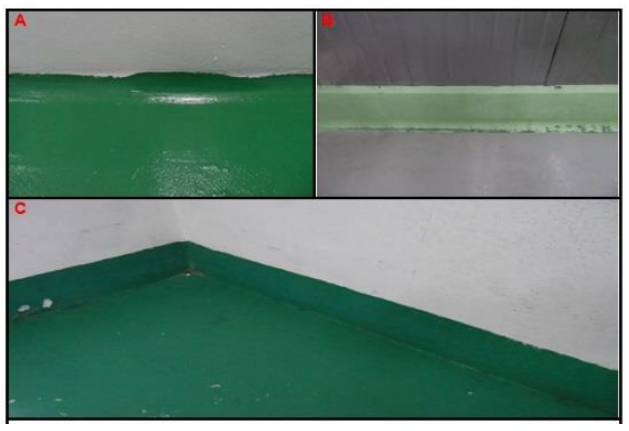

Figure.3. Floor curve

The walls for food premises must be easy to clean, well-maintained and have a height of at least 8 feet. The height of 8 feet is the minimum height from floor to ceiling in the interior of the premises. There is a variety of materials that can be used for the interior wall construction of food premises, such as concrete, PU panel, fiberglass panel, epoxy, tiles, gypsum board and stainless steel (Federal Register, 1997; Cramer, 2003; MOH, 2010; Schmidt \& Erickson, 2014). For the production of dry pre-mixed coffee products, Photo A in Fig. 2 shows the company's use of gypsum board for building interior walls. This building material is cheaper and easier to work with in terms of cleaning the dust generated in the production, and this can be solved by providing a dust evacuator in the mixing chamber. Other processing areas have no dust as the production process is conducted in processing areas that are completely closed. As for frozen products, Photo B in Fig. 2 shows the construction material used is stainless steel, which does not rust. The use of stainless steel in this industry is very suitable to maintain the ambient temperature process in a state of constant cold. However, stainless steel will contribute to condensation and is expensive (Schmidt \& Erickson, 2014). The advantages of stainless steel allow the cleaning and sanitizing works to be conducted effectively on the inner wall surface if there is dirt. Photo $C$ in Fig. 2 refers to a company producing paste and drinking water products that uses half concrete walls and tiles as building materials. The use of this building material is found to be unsuitable because, in the process of producing the paste, the product may splash on the walls surface as they are being. Part of the concrete used is not coated with epoxy, which will cause the rest of the product to be difficult to wash off.

Floor and wall joints must have curves or not angled at $90^{\circ}(\mathrm{MOH}, 2010)$. The requirement of curves is to ensure that cleaning and sanitation can be carried out effectively and to avoid stagnant water that is known to allow the accumulation of dust and microbial growth (Federal Register, 1997; Cramer, 2003; Moerman, 2010). There is a variety of materials used for the construction of curves, namely cement and epoxy coating, and stainless steel plate pieces. The use of cement is suitable for facilitating adhesives with the floor and wall surfaces, but it needs to be coated with epoxy to ensure a smooth surface. Meanwhile, the fabrication of stainless steel plate pieces is also often used but requires an appropriate size to the adhesion between the wall and floor. The angle of curves required between the wall and the floor is a radius of 1 inch or more (Schmidt \& Erickson, 2014). The purpose of the size of the curve is to enable the smooth flow of water during cleaning and sanitation activities. If the size of the curve is too small, it may cause uneven water flow that may stagnate in the available corners. 
Photos in Fig. 3 show the type of material and size of the curve built in the respondent companies. Photo $A$ in Fig. 3 shows companies using cement base material coated with epoxy for the curve between the gypsum board and floor. The size may exceed the 1-inch radius proposed by Schmidt \& Erickson (2014) to ensure good water flow for cleaning and sanitation activities. Meanwhile, Photo B in Fig. 3 shows the construction of a stainless steel wall that is placed on a two-foot concrete foundation. The purpose of a two-foot concrete foundation is to prevent construction wall materials to be exposed to water and chemicals during cleaning and sanitation activities. If the building does not use concrete as the building's foundation, difficulties will arise when designing the curve. The size of the curve is not so large compared to the size of Company A. However, the approximate 1-inch radius is sufficient for the flow of water and prevents the accumulation of dust. Photo $C$ in Fig. 3 shows no curve built with a $90^{\circ}$ angle between the floor and wall. This angle will collect dust, leftover food and water, in addition to the difficult work of cleaning and sanitation. The company has been certified for GMP and HACCP, which means that the authority has confirmed the premise of the plan is in compliance with the requirements of GMP and HACCP. Inconsistencies of audit practice by the authority on the need to involve infrastructure will be followed in the construction of the building plan by the industries.

\subsection{Door}

Photo A in Fig. 4 shows the use of plastic materials for the building of doors. The use of plastic material is found to be more suitable as it is washable against any dirt or dust and is resistant to corrosion because the products produced by the industry are in the form of powder. Meanwhile, Company B (Photo B) uses PU panels which are found to be appropriate for maintaining the temperature of the room environment for frozen product processing in addition to being easy to be cleaned and resistant to moisture. The use of half glass doors with aluminium frames and gypsum board in Photo C (Fig. 4) is implemented by the company producing paste and drinking water products. Normally, this type of door is used by many companies that manufacture health products. The doors of this type have various drawbacks including the occurrence of impurities on the surface of gypsum board aside from the difficulty to be cleaned as well as the glass used being likely to break due to unwanted handling error that allows physical contamination to the products or other facilities. According to the standard requirements of MS 1514: 2009, there is no need to set the self-closing doors required to be either a door or door room processor. The requirements of MS 1514: 2009 have been set only for the use of self-closing toilet doors. The doors on the building of food premises should be of self-closing because of the benefits including avoiding the entry of insects in the production or building premises and to maintain a continuous positive airway pressure, especially for the processes that have a high level of cleanliness. Photo B in Fig. 4 shows an installation of a self-closing door because the nature of the frozen food production process requires temperature maintenance of industrial environments compared to other respondents. The installation of the door leaf type is usually taken for granted by most food companies without considering the impact of the air pressure in it. When mounting the door, especially in rooms with high levels of cleanliness and high risk products such as baby food processing or preparation of readyto-eat food, this may cause dirty air to be swept into the processing area and air pollution will occur. Opening the door leads to the flow of clean air from the area to a lesser degree of cleanliness (Smith, 2006).

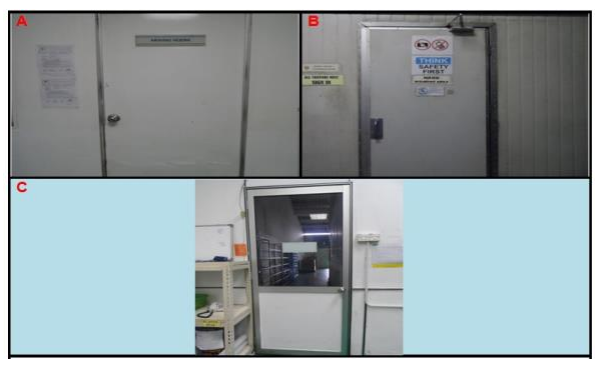

Fig. 4. Door facilities 


\subsection{Toilet}

Fig. 5 shows photos $A, B$ and $C$ regarding the construction of the toilet using tiles. In regards to the issue of the tile floor, all three companies did not provide a curved angle between the floor and wall to facilitate cleaning and sanitation activities. Toilet floors should be built from materials that are resistant to water, such as ceramic tiles and concrete with a curve between the floor and wall (Lelieveld et al., 2005). The requirements of MS 1514: 2009 have stated that for the compliance with the requirements of GMP, the toilet needs to provide self-closing doors. The same is also underlined by the Federal Register (1997) for building toilets in meat processing plants.

Folding doors do not allow self-closing and are not permitted to be used in toilet construction. When the toilet is in the production area, the industry must ensure that control actions can manage the pollution sources concerned with the possibility of airborne contamination or food handlers who use the toilet. Control needs to be done by providing two layers of doors to prevent the opening of the toilet door directly into the production area (MS 1514: 2009; $\mathrm{MOH}, 2010$ ) and to establish an area of medium hygiene level to enable staff to change clothes before entering the toilet (Smith, 2006). In this study, it was observed that all the toilets in the companies were located out of production areas. The toilet area is one of the areas with negative air pressure through the assembly of the exhaust fan (Lelieveld et al., 2005). It was observed in Photo B in Fig. 5 the installation of the exhaust fan in the toilet to ensure the air pressure in the toilet is negative and facilitate air flow from the high pressure area. The high pressure air from the production area will continue to flow into the dirty air area. The area that has a high level of cleanliness must have a high pressure (positive) compared to the surrounding areas (Smith, 2006). The principle that should be used is the flow of air from the high to less clean zone (Codex, 1999).

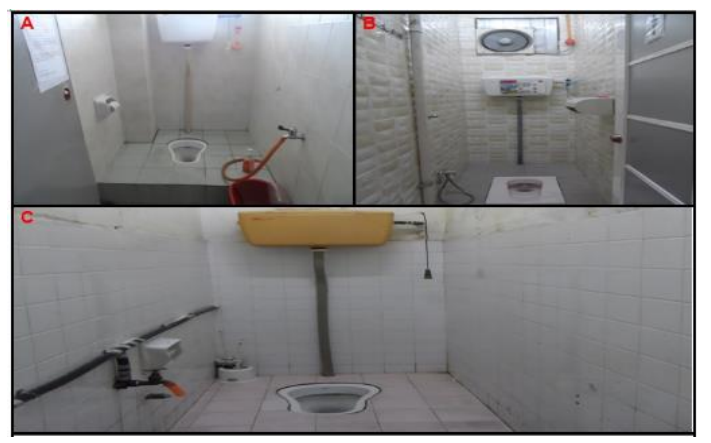

Fig. 5. Toilet facilities

\subsection{Changing Room}

Fig. 6 shows photos $A$ and $C$ that show lockers made of metal, which are coated with a temporary coating material, and Photo $B$ that displays lockers made of plastic material. Lockers should be constructed of resistant materials which are rust-proof, easily cleaned and inspected, resistant to moisture, light, have beautiful colours, a smooth surface, and a sloped upper surface (Federal Register, 1997). Photos A, B and C in Fig. 6 do not have locker facilities on the slope surface. Lockers must be placed near to the wall and the top surface of the slope is $30 \%$ to prevent the accumulation of dust and dirt (Lelieveld et al., 2005; Schmidt \& Erickson, 2014), although the needs are not stated as a requirement of MS 1514: 2009. The slope of the surface is also to prevent it from being a location to place staff belongings as can be seen in Photo C (Fig. 6). The flow of labour movement and position of the locker room are important. Areas of high hygiene level shall have a dressing room where workers can change clothes to wear protection. Employees are not allowed to go to the toilet or canteen without first changing clothes, even if the procedure requires a frequent change of clothes as it is important to prevent contamination brought by the workers to the production area after entering the toilet or canteen (Smith, 2006). Furthermore, the Federal Register (1997) also outlined the conditions in which the entry to the bathroom through the dressing room should not 
come directly from the production area or storage room. After changing clothes in changing rooms situated in areas of lower hygiene level such as outside the operating area of the plant, it is highly likely the protective clothing will be contaminated and will bring contamination into the processing area that is at a high level of cleanliness. This condition may occur in small and medium-sized industrial premises where the dressing rooms are built far away and not connected with the processing area. Thus, the workers have to go through a dirty area with clean attire again before entering the processing area. This situation is observed to occur in Company $\mathrm{C}$. The concept of worker passage is not as outlined by the Ministry of Health ( $\mathrm{MOH})$. Guidelines and checklists provided by $\mathrm{MOH}$ have prepared a concept that shows the direction of movement of workers that must first go through the locker room before entering the processing area (MOH, 2010).

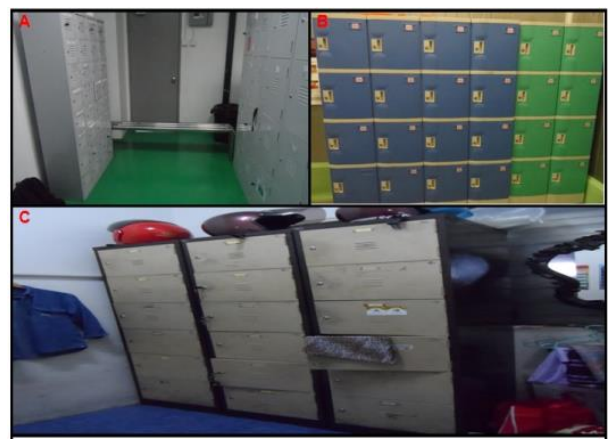

Fig. 6. Changing room facilities

\subsection{Ventilation and Air Quality}

Photos A, B, and C in Fig. 7 (left) show the use of exhaust fans installed in the building, especially in areas involving heat and toilets. While the installation of exhaust fans is good, especially in the toilets, however, it will also cause a negative pressure in the area. In the event of the opening of the area such as opening windows, doors, vents or ceiling of the building, the outside air is not controlled; it will cause airborne contamination to the product or food contact surfaces (Graham, 2011). Thus, companies need to ensure that the areas that have exhaust fans should have a good ventilation system to ensure that pressure is always positive in these areas (Graham, 2004). Moreover, the maintenance and cleaning of the exhaust fans should be done continuously. Photo C (left) in Fig. 7 shows the exhaust fan is not sufficiently clean and maintained.

Photo A in Fig. 7 (right) shows the use of a centralized ventilation system where air flows through a hose to every area of the industrial premise. Photo B (right) in Fig. 7 shows the unit ventilation system is installed vertically with the air compression unit placed on the ceiling. Installation of this ventilation unit in frozen food production plants with the use of stainless steel ceiling panel will result in condensation. The situation becomes worse if your desk or product is positioned below the ventilation unit. Photo $\mathrm{C}$ (right) in Fig.7 shows the installation of a ventilation system in split units horizontally on the wall of the premise. Dust is easily formed on the surface of the unit and this makes it difficult for maintenance work and cleaning. The air pressure zone with the most positive air pressure is the area where the final product is exposed to air, which is usually after the removal step and where the blended product is packaged or wrapped and closed. If there is no such removal step in the production of ready-to-eat products, the entire area should be preserved as an area of high pressure (Graham, 2011). 

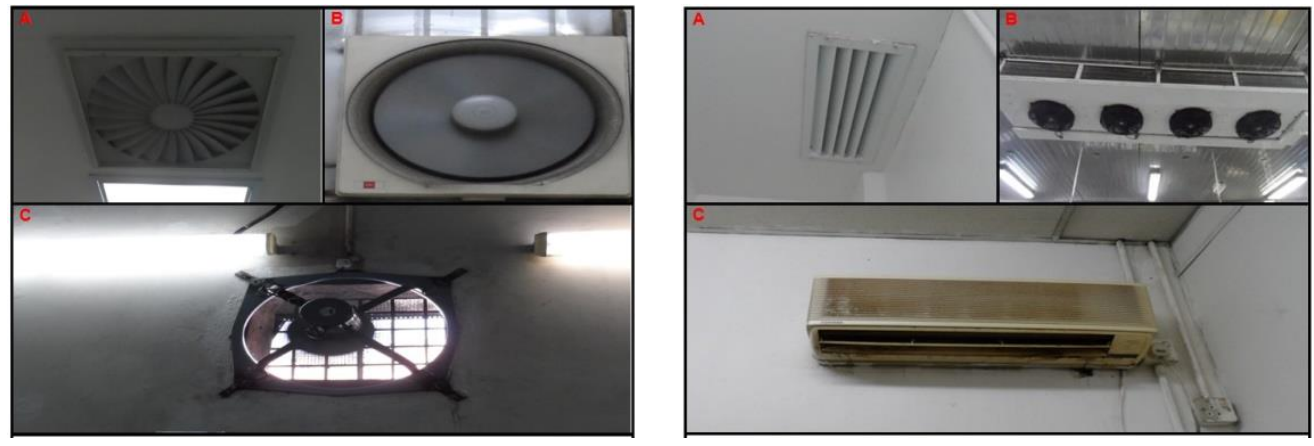

Fig. 7. Ventilation and air quality

The use of air conditioners, exhaust fans and hoods are intended to control the flow of air. Exhaust fans and hoods are usually used to remove dust contained in the air for the process (Graham, 2004), while the hood is used to remove heat when the process involves high temperatures. Air conditioners are ventilation systems through filtering incoming air to create a difference in the air pressure of an area other than the process to create a comfortable work environment (Schmidt \& Erickson, 2014). Ceiling fans and standing fans are used by SME workers while performing work processes. No explanation was given in respect of whether or not both types of fan can be used in the food industry, whether in MS 1514: 2009, guidelines and checklists by MOH, or the literature review. Ceiling fans and standing fans will cause dust distribution throughout the area and all surfaces in contact. Additionally, the friction surface with air fans will create an electrostatic charge and a place to collect dust. Bad ventilation in a high hygiene level will increase the environmental temperature between $20-38^{\circ} \mathrm{C}$ that is optimal for the growth of most microorganisms (Vank Don \& Gaalman, 2004). If compressed air is used for products or surfaces in contact with food, it must use an HEPA filter with $99.7 \%$ efficiency rate at $1 \mu \mathrm{m}$ (Lelieveld et al., 2005).

The requirements of MS 1514: 2009 do not explain the types of air conditioners that are safe for use in the food industry. If viewed from the position of installation of these units in the respondent companies', there are split units that will be installed in each area either horizontally or vertically, while centralized units only hose through the ceiling vertically to each process area in which the compressor and the air filter are placed in a specific location outside of the processing area. The disadvantages of using horizontally installed split units are that it will cause the accumulation of dust on the surface of the units and it requires constant cleaning. Furthermore, when the work involves cleaning and maintenance, dirt or dust will be scattered on the surface of the product and be in contact with food, especially when carried out in areas with high hygiene such as packaging. This situation can be avoided by using centralized installation units where maintenance work will occur above the ceiling or outside the process as in Photo A (right) in Fig. 7. Among the causes of this issue is that the installation of a centralized unit is expensive compared to normal split air conditioning units. Furthermore, the cost of infrastructure is another issue that hinders the design and preparation of GMP premise infrastructure (Tomasevic et al., 2013; Hasnan et al., 2014).

\subsection{Lighting}

Photo A, B and C in Fig. 8 show the respondent companies' industrial lamps found in their food premises. Photo A in Fig. 8 shows the hardware planted bulbs in the ceiling in order to reduce exposure to the environment as to minimize the surface which may be a place of collecting dust. Photos $B$ and $C$ in Fig. 8 show the hardware is exposed to light production environments and require more complicated maintenance and cleaning activities because of dust collection on the lamp. In this study, it was observed that all company respondents have adequate light intensity for their operations. Basically, less light intensity is needed in the reception area of raw materials and delivery area with only 100 lux and 215 lux at minimal processing areas (Lelieveld et al., 2005; Schmidt \& Erickson, 2014). The confusion over this issue is due to the industry neglecting to know the lighting requirements needed by a process and in the area of food premises. Furthermore, the industry did not make any measurement of light intensity during the construction of the premises and instead relied only on the power of vision, which it considers appropriate 
for any work on the premises. Cleaning should be done on the surface of the lamp or light box that may collect dust and debris if left uncleansed for too long. Among the reasons to have a high 8 foot ceiling from the floor is to facilitate cleaning activities and the hardware lamp as the light source would attract insects.

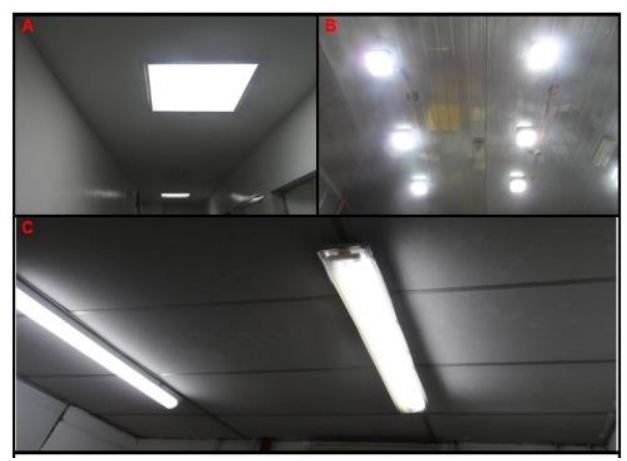

Fig. 8. Lighting

\subsection{Storage}

Photo $A, B$ and $C$ in Fig. 9 show the dry storage area for raw materials of the industry respondents. Photo $A$ in Fig. 9 shows completely packaged raw materials placed on wooden pallets with a floor height of about 6 inches and 2 feet from the wall surface. Photo B in Fig. 9 shows the ingredients in sealed bottles placed on metal shelves painted and sealed to the wall and with a shelf height from the floor of about 6 inches. Nevertheless, there are raw materials stored close to the ceiling surface. Raw materials should be kept at least 2 feet from the ceiling surface. Photo $\mathrm{C}$ in Fig. 9 shows the material stored in boxes placed on wooden pallets. For the use of wooden pallets, the stored materials must have a complete packing to prevent physical harm or contact with microbes on the surface of the pallet. The use of pallets as a place to put the packaged finished product or raw material is a norm in the industry. However, it is not evident whether this requirement is justified by GMP food premises or not. According to Powitz (2005), the rack for dry storage of raw materials can be made of hard wood, hard plastic or metal that does not rust. This statement shows that wooden pallet can be used for dry storage of raw materials. Furthermore, this is not explicitly stated in the requirements of MS 1514: 2009 as well as the guidelines and checklists by MOH (2010). The confusion stems from the concern about a piece of wood that may be present in the raw material during the processing stage and contribute to physical hazard. In order to prevent any potential hazard, they do not approve the use of wooden pallets in the food industry even for storage.

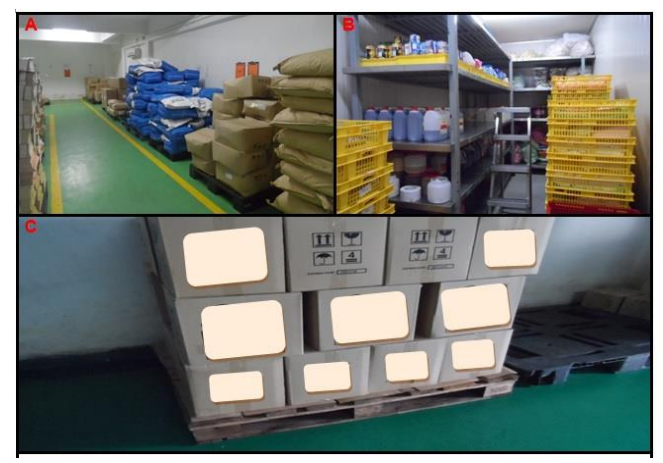

Fig. 9. Storage area facilities 
Another aspect of confusion observed in all company respondents in relation to storage was the location of storage area and lack of buffer zone to control incoming material to the production area. Ranking stores in addition to the manufacturing industry is to improve the efficiency of the process by ensuring that the stores are located as close as possible (Van Donk \& Gaalman, 2004). However, things are different in the food industry as it is an area with a hygiene control and this storage aspect will affect the quality and hygiene of products. Raw materials or packaging materials entering the high level of cleanliness must first go through a buffer area to limit the hazard that was brought to the high level of cleanliness (Smith, 2006). Thus, the position of the store in food premises is important not just to improve the efficiency of the production process alone but also to determine the appropriate control for controlling the movement of materials across the layout plan.

\subsection{Conclusion}

There are some confusions prevailing in the industry regarding the design and facilities for the first element of GMP system. This confusion extends from building materials, design and construction features, and facilities. The need to provide a document of guidance on this matter as additional information to MS 1514: 2009 is critical.

\section{Acknowledgement}

This research was self-funded and supported by SIRIM Training Services Sdn Bhd and SIRIM Berhad.

\section{References}

Bai, L., Ma, C., Yang, Y., Zhao, S., \& Gong, S. (2007). Implementation of HACCP system in China: a survey of food enterprises involved. Food Control, 18, 1108-1112.

Celaya, C., Zabala, S., Pirez,P., Medina, J., Maras, J., Fouz, J., Alonso, R., Anton, A., \& Agundo, N. (2007). The HACCP system implementation in small business of Madrid's community. Food Control, 18(10), 1314-1321.

Codex Alimentarius (1999). Principles and guidelines for the conduct of microbiological risk assessment.

Cramer, M.M. (2003). Six steps to effective sanitary design for the food plant. Food Safety Magazine, Feb/March 2003.

Cramer, M.M. (2008). Food plant sanitation: Have you found your niche? Food Safety Magazine, October/November 2008.

Department of Veterinary Services (DVS). (2013). Manual Procedure Veterinary Health Mark.

Djekic, I., Tomasevic, I., \& Radovanovic, R. (2011). Quality and food safety issues revealed in certified food companies in three Western Balkans countries. Food Control, 22(11), 1736-1741.

Doménech, E., Amorós, J. A., Pérez-gonzalvo, M., \& Escriche, I. (2011). Implementation and effectiveness of the HACCP and pre-requisites in food establishments. Food Control, 22(8), 1419-1423.

Graham, D.J. (2004). Using sanitaty design to avoid HACCP hazards and allergen contamination. Food Safety Magazine, June/July 2004.

Graham, D.J. (2011). In-plant handling and food safety: There is a connection. Food Safety Magazine, June/July 2011.

Griffith, C.J., Livesey, K. M., \& Clayton, D. A. (2010a). Food safety culture: the evolution of an emerging risk factor? British Food Journal, 112 (4), 426-438.

Griffith, C.J., Livesey, K. M. \& Clayton, D. A. (2010b). The assessment of food safety culture. British Food Journal, 112(4), 438-456.

Hasnan, N. Z., N. Aziz, N. A., Zulkifli, N., \& Taip, F. S. (2014). Food factory design: Reality and challenges faced by Malaysian SMEs. Agriculture and Agricultural Science Procedia, 2, 328-336. 
Karaman, D. A., Cobanoglu, F., Tunalioglu, R., \& Ova, G. (2012). Barriers and benefits of the implementation of food safety management systems among the Turkish dairy industry: A case study. Food Control, 25(2), 732-739.

Lelieveld, H.L., M. Mostert, M.A., \& Holah, J. (2005). Handbook of hygiene control in the food industry. England: Woodhead Publishing Limited.

Lombardo, T. (2014). Food Plants SOPs: The backbone of your food safety system. Food Safety Magezine, Dec 2013/January 2014.

Losito, P., Visciano, P., Genualdo, M., \& Cardone, G. (2011). Food supplier qualification by an Italian Large-scale-Distributor : Auditing system and non-conformances. Food Control, 22(12), 2047-2051.

Malaysian Standard MS 1480: 2007. Food Safety According to Hazard Analysis and Critical Control Point (HACCP) system. Department of Standard Malaysia (First revision).

Malaysian Standard MS 1514: 2009. Good Manufacturing Practice (GMP) for Food. Department of Standard Malaysia (First revision).

Ministry of Health (MOH). (2010). Garis panduan dan senarai semak pengusaha industri makanan.

Moerman, F. (2010). Hygienic design of food processing facilities. Food Safety Magazine, October/November 2010.

Mukentwali, C., Laswai, H., Tiisekwa, B., \& Wiehler, S. (2013). Good manufacturing and hygiene practices at small and medium scale pineapple processing entreprises in Rwanda. Food Science and Quality Management, 13, 15-30.

Panisello. P.J., \& Quantick. P.C. (2001). Technical barriers to hazard analysis critical control point (HACCP). Food Control, 12, 165-173.

Powitz, R. W. (2005). Shedding light on the art and science of lighting. Food Safety Magazine, October/November 2005.

Schmidt, R. H., \& Erickson, D. J. (2014). Sanitary Design and Construction of Food Processing and Handling Facilities. FSHN 07-03, Department of Food Science and Human Nutrition, Florida Cooperative Extension Service, IFAS, University of Florida 1, 1-8.

Smith, D. (2006). Design and management concepts for high care food processing. British Food Journal, 108(1), 54-60.

Tomasevic, I., Tomi, N., \& Rajkovi, A. (2013). Serbian meat industry: A survey on food safety management systems implementation. Food Control, 32, 25-30.

USDA/NCD \& CS (1997). Facility guidelines for meat processing plants. Federal register, 62(164), 45027-45044.

Van Donk, D.P., \& Gaalman, G. (2004). Food safety and hygiene: systematic layout planning of food process. Chemical Engineering Research and Design, 82 (A11), 1485-1493.

Wallace, C.A., Holyoak, L., Powell, S.C., \& Dykes, F. C. (2014). HACCP- The difficulty with Hazard Analysis, Food Control, 35, $233-240$.

Wallace, T., \& Williams, T. (2001). Pre-requisites: a help or a hindrance to HACCP. Food Control, 12, 235-240. 